\title{
A Long-Term Control Study of the Treatment of Cervical Radiculopathy by Percutaneous Endoscopic Posterior Cervical Discectomy and Anterior Cervical Decompression, Bone Graft Fusion and Internal Fixation
}

\section{Xiaodong Huang}

Guangzhou Medical University

Weiheng Wang

Changzheng Hospital

\section{Qingxi Meng}

PLA North Military Command Region General Hospital

Jiangming Yu

Changzheng Hospital

Xiaojian Ye ( $\nabla$ xjyespine@smmu.edu.cn )

Changzheng Hospital

\section{Research article}

Keywords: percutaneous endoscopic posterior cervical discectomy, anterior cervical decompression and fusion, cervical spondylotic radiculopathy, cervical foraminal stenosis, cervical disc herniation

Posted Date: September 23rd, 2020

DOl: https://doi.org/10.21203/rs.3.rs-78852/v1

License: (c) (i) This work is licensed under a Creative Commons Attribution 4.0 International License.

Read Full License 


\section{Abstract}

\section{Background}

Cervical spondylotic radiculopathy (CSR) is very common all over the world. However, there are only a few reports about the efficacy of percutaneous endoscopic posterior cervical discectomy (PEPCD) in the treatment of CSR. Anterior cervical decompression and fusion (ACDF) and PEPCD which is a better way to treat CSR need further study.

\section{Methods}

From January 2015 to December 2016. A retrospective study of 70 patients undergoing surgery for CSR (33 using PEPCD and 37 using ACDF). The intra-operative parameters, neck disability index (NDI), neck and arm visual analog scale (VAS) score were used to assessed clinical outcome. Radiological outcomes were assessed by measuring cervical 2-7 (C2-7) lordosis, disc height index (DHI), and degree of degenerative changes at the corresponding level.

Results

The mean follow-up period was 48.5 month (36-66 months). Two groups can significantly improve the clinical symptoms. There was no significant difference between the two groups in clinical results (VAS, $\mathrm{NDI}$ ). Compared with preoperative, the lordosis of $\mathrm{C} 2-7$ increased significantly at the last follow-up. At the last follow-up, C2-7 lordosis in the ACDF group was significantly higher than that in the PEPCD group. In PEPCD, compared with preoperative, there was no significant difference in the $\mathrm{DHI}$, but the degree of disc degeneration was significantly increased at the last follow-up.

\section{Conclusion}

For patients with CSR, PEPCD had similar clinical early and intermediate outcomes when compared with ACDF, with the advantages of minimally invasive. PEPCD is a sufficient and safe supplement and alternative to conventional surgery.

\section{Introduction}

Cervical spondylotic radiculopathy (CSR) refers to a series of secondary pathological changes that occur on the basis of degenerative changes in the intervertebral disc. These pathologic factors interact with intervertebral disc degeneration, oppressing the corresponding nerve roots, thereby eliciting clinical manifestations of pain and dysfunction [1,2]. The disease is slow onset, and more common in the population aged 40-60, with long-term unhealthy posture. The natural history of most patients is selflimited [3]. The symptoms were relieved after conservative treatment in most of the patients. When conservative treatment does not work, surgery is required [4]. 
Traditional surgical treatment of CSR includes ACDF [5-7]and posterior cervical intervertebral incision, the "keyhole" surgery [8, 9]. ACDF was initiated by Robinson et al. in the 1950s [5], which is widely used in the treatment of cervical spondylosis, and gradually become a standard for treatment of cervical disc disease $[6,7,10]$. While ACDF showed a certain degree of prosthesis sedimentation, dislocation and false joint formation and other complications [11-13]. Compared with ACDF, posterior surgery has the following advantages: First, because the back of the cervical spine without significant vascular and nerve structure, so the possibility of damage to vascular nerves is low [14]; Second, posterior surgery can be effective decompression on the proliferation of articular processes and prominent intervertebral disc induced neural root canal stenosis, to avoid the ACDF fusion failure, prosthesis sedimentation and pseudarthrosis and other risks [15]. However, the open posterior cervical spine surgery has many disadvantages, such as large trauma, bleeding, wide range of paraspinal muscles need to be stripped, neck pain and dysfunction [16]. In addition, there is a loss of the lordosis of the cervical spine and the potential risk of sagittal deformity after long segment decompression [17].

With the development of minimally invasive spine surgery, the development of endoscopy has made remarkable achievements [18-21]. Micro Endoscopic Discectomy (MED) [19, 22] and percutaneous endoscopic assisted intervertebral foramen expansion and nucleus removal $[21,23]$ are widely used at present. MED can use the microscope to amplify the field, so that the operation is more accurate. Compared with the traditional open surgery, the muscle stripping range is greatly reduced, short hospital stay, less intraoperative bleeding and less postoperative complications [24]. Due to surgery need to use the channel for a long time to distract the muscles, postoperative muscle pain and muscle spasms may occur, and the risk of dural rupture is relatively high [25]. At present, almost all of the lumbar disc herniation can be done through the endoscope [21]. PEPCD is an extension and progression of posterior cervical MED technique. Using transcutaneous endoscopic technique, the field is directly projected through the electronic imaging system to the display screen, making the surgical trauma smaller, more accurate, less bleeding, shorter hospital stay, and fewer complications [21, 23, 26, 27]. Limited paper reported effect of PEPCD on the treatment CSR. According to intra-operative parameters, clinical outcomes, complication and recurrence, ACDF and PEPCD which is a better way to treat CSR need further study. Moreover, there are few reports about the difficulties of localization and intraoperative bleeding during PEPCD operation.

The purpose of this retrospective study was to (1) provide comparative data regarding clinical outcomes using well-established patient-reported outcome measures in patients undergoing surgery for CSR using either PEPCD or ACDF. (2) discusses the problems of rapid location and intraoperative bleeding during PEPCD operation.

\section{Materials And Methods}

A retrospective analysis was performed on 70 patients diagnosed with CSR and underwent cervical spine surgery. From January 2015 to December 2016, 412 cases of cervical spine surgery performed by an experienced doctor (Xiaojian Ye) were collected and stored in the Changzheng Hospital Orthopedic 
Medical Database. According to the following inclusion and exclusion criteria, 70 patients diagnosed with single-segment CSR were treated with PEPCD or ACDF. medical history and physical examination, NDI and VAS (neck and upper limb) score, cervical X-ray, MRI and CT were used to determine the clinical outcome. All patients were scheduled for follow-up at 3, 6, and 12 month and after each year postoperatively through an outpatient or telephone consultation.

\section{Inclusion/exclusion Criteria}

The inclusion criteria for this study were: (1) older than 20 years old. (2) a clear diagnosis of singlesegment CSR, and at least 8 weeks of strict conservative treatment is invalid. (3) The surgical segment is a single segment in C2-T1 and is operated by ACDF or PEPCD.

The exclusion criteria for this study: (1) Existence of cervical surgery contraindications. (2) Having surgery, trauma, infection, or cancer history of neck. (3) Multi-segmental CSR. (4) Cervical spondylotic myelopathy, extensive post-toughening with ossification, or simple axis of the neck pain without nerve root symptoms. (5) Patients who can not tolerate general anesthesia or surgery.

\section{Surgical Technique}

ACDF:

Under general anesthesia, the patient is supine in the operating bed, and the neck is in the extended position to increase the intervertebral height of the target segment. Use $\mathrm{C}$ arm machine for positioning. In the right side of the neck skin for a length of about $3 \mathrm{~cm}$ transverse incision, and layer by layer exposed to the target intervertebral space. Removal of the intervertebral discs and the compression of the spinal cord and nerve roots, including prominent nucleus pulposus, osteophyte and posterior longitudinal ligament. Scrape the cartilage lamina, but to protect the bone plate to prevent the sedimentation of the implant. Preoperative evaluation and intraoperative measurement to select the appropriate size of the Zero-P (Johnsonn). Zero-P was filled with autogenous bone or artificial bone, and then use Zero-P's own screws to fix. Rinse the surgical area, stop bleeding, rinse again, and then sutured the incision layer by layer. Complete surgery. After the operation, the patients were treated with dehydrating agents and neurotrophic drugs. The second day after surgery under the protection of the neck support to get out of bed activities, and neck support needs to wear 2-4 $\mathrm{w}$.

PCPED:

PCPED was performed using the TESSYS TM system (Joimax, Germany). The patients were placed in the prone position on a customized plaster bed, and the neck was slightly buckled to increase the intervertebral space size of the target segment and reduce the overlap of small joints under general anesthesia. Double upper limbs close to the trunk, fingers toward the tail, the patient's head and double upper lip with a fixed with tape (figure. $1 \mathrm{~A}$ ). Use $\mathrm{C}$ arm machine for auxiliary positioning. Two $20 \mathrm{G}$ long positioning needles were punctured at about $1.5-2 \mathrm{~cm}$ on the outside of the spinous process of the target gap (figure.1 B), and locate the needle at the K point by fluoroscopy (K point: the focal point of the upper 
lamina, the lower lamina and the connection of the medial margin of the adjacent facet figure.1D). A longitudinal skin incision with a length of about $0.8 \mathrm{~mm}$ is positioned at the positioning needle, and the guide needle is inserted into $\mathrm{K}$ point, and the expansion sleeve is gradually arranged until the work channel. When the channel is in a good position (figure.1C), take out the guide wire and the expansion sleeve, and put into the intervertebral disc endoscope. $0.9 \%$ of the saline hanging in the top of the patient about $1.5 \mathrm{~m}$, adjust the flow rate about 50-100 $\mathrm{ml} / \mathrm{min}$, connected to the endoscopic device for continuous lavage. Radiofrequency ablation and hemostasis under endoscope. The lower edge of the upper lamina and the upper edge were removed by grinding and laminectomy ( $3 \mathrm{~mm}$ of the medial margin of the facet joint). The range of bite is within $1 / 3$ of the articular process (Figure.1D\&Figure.2 A-D). Using the blue tweezers to remove some of the ligamentum flavum, the epidural venous plexus was coagulated by bipolar radiofrequency electrode to maintain a clear visual field and accurately identify nerve roots. According to the imaging data of the patients, the decision was made to expand the intervertebral foramen or remove the nucleus pulposus. When the intervertebral foramen stenosis, you can use the bite forceps and power grinding (Stryker, USA) to expand the intervertebral foramen. Decompression was performed until proximal and distal pedicles were confirmed longitudinally, a probe was then easily inserted through the foramen to confirm adequate neural decompression. When the disc is prominent, using nerve root probe to explore the nerve root axillary and nerve root shoulders, to determine the location of the nucleus pulposus; use nucleus pulposus gradually remove the prominent nucleus until the nerve root completely released (Figure.2 C-E). The fiber ring and the soft tissue around it were ablated by radio frequency electrode. When the dura mater beat was good, the decompression was complete. Use radio frequency to stop bleeding, rinse the area, take out the intervertebral foramen mirror and channel, suture the incision and complete the operation (Figure.2 F). Because of the small incision of the PEPCD, it is not necessary to have a drainage tube after operation, and the silica gel can be placed for drainage and remove within 24 hours after operation. After the operation, the patients were treated with dehydrating agents and neurotrophic drugs. The second day after surgery under the protection of the neck support to get out of bed activities, and neck support needs to wear 5-7 d.

Figure.1 Position and orientation during operation. A: the patient in the prone position on a customized plaster bed; B: Two positioning pins used to determine the target gap and $\mathrm{K}$ point; $\mathrm{C}$ : The cervical spine radiograph shows that the expansion sleeve is located near the $\mathrm{K}$ point of the gap; $\mathrm{D}$ : Three dimensional CT display of $\mathrm{K}$ point and the range of intraoperative laminectomy.

Figure.2 Intraoperative visual field and postoperative incision. A: Dynamic grinding system for removal of lamina; B: Vertebral lamina and ligament were removed by the biting forceps; C: Nerve root probe to detect nerve root canal and nerve root; D®Removal of herniated intervertebral disc tissue; $\mathrm{E}$ : The prominent nucleus pulposus was removed during operation; F: Postoperative incision.

\section{Intraoperative outcome Measure}

According to the patient data and operation records, the operative segment, operation time, amount of bleeding, complications, LOHS (length of hospital stay), and time to return to normal work of the two 
groups were recorded and compared.

\section{Postoperative outcome evaluation}

The NDI, neck and arm VAS score, X-ray, MRI and CT were evaluated on the day before surgery and $3 \mathrm{~m}, 6$ m, $12 \mathrm{~m}, 24 \mathrm{~m}, 36 \mathrm{~m}, 48 \mathrm{~m}, 60 \mathrm{~m}$ and the last follow-up after surgery. The Cobb angle of cervical was measured by C2-7 Iordosis (Figure.4 B) [28], and DHI was measured by Emery [29]. According to the modified Pfirrmann classification, the degree of cervical disc degeneration was evaluated before and after operation [30]. According to the preoperative and the last follow-up of the cervical dynamic X-ray film to determine whether the existence of cervical instability: intervertebral angle $>10^{\circ}$ or displacement $>3$ $\mathrm{mm}$ to determine intervertebral instability.

\section{Statistical Analysis}

Mean outcome scores for NDI, neck and arm VAS were compared for each follow-up period. Statistical analysis was conducted with the Student t-test, with $P<0.05$ considered significant.

\section{Results}

\section{Patient Characteristics}

As showed in the table.1 and table.3, the baseline of patient characteristics was well matched. There was no statistical difference in the age, height, weight and BMI ( $P>0.05)$ in both groups. In PEPCD, the mean age was $55.52 \pm 13.19$ and there were 10 (30.3\%) females. In ACDF, the mean age was $52.24 \pm 10.17$ and there were $14(37.84 \%)$ females. There was no significantly difference in the baseline of NDI (mean 27.26 \pm 9.66 [PEPCD] vs $29.13 \pm 9.40$ [ACDF]; $P=0.42$ ) and ram VAS (mean $6.74 \pm 1.88$ [PEPCD] vs $6.92 \pm 1.60$ [ACDF]; $P=0.67)$. while the preoperative neck VAS score in ACDF $(2.92 \pm 1.55)$ was much higher than that in PEPCD $(2.06 \pm 1.44, P=0.02)$. The most frequent operative levels were $C 5 / 6$ and $C 6 / 7$ in $23(69.70 \%)$ in PEPCD, and in 25 (67.57\%) in ACDF. While the PEPCD patients reported longer preoperative duration of symptoms (mean $12.85 \pm 16.53[\mathrm{PEPCD}]$ vs $5.84 \pm 5.51$ [ACDF]; $P=0.02$ ). 


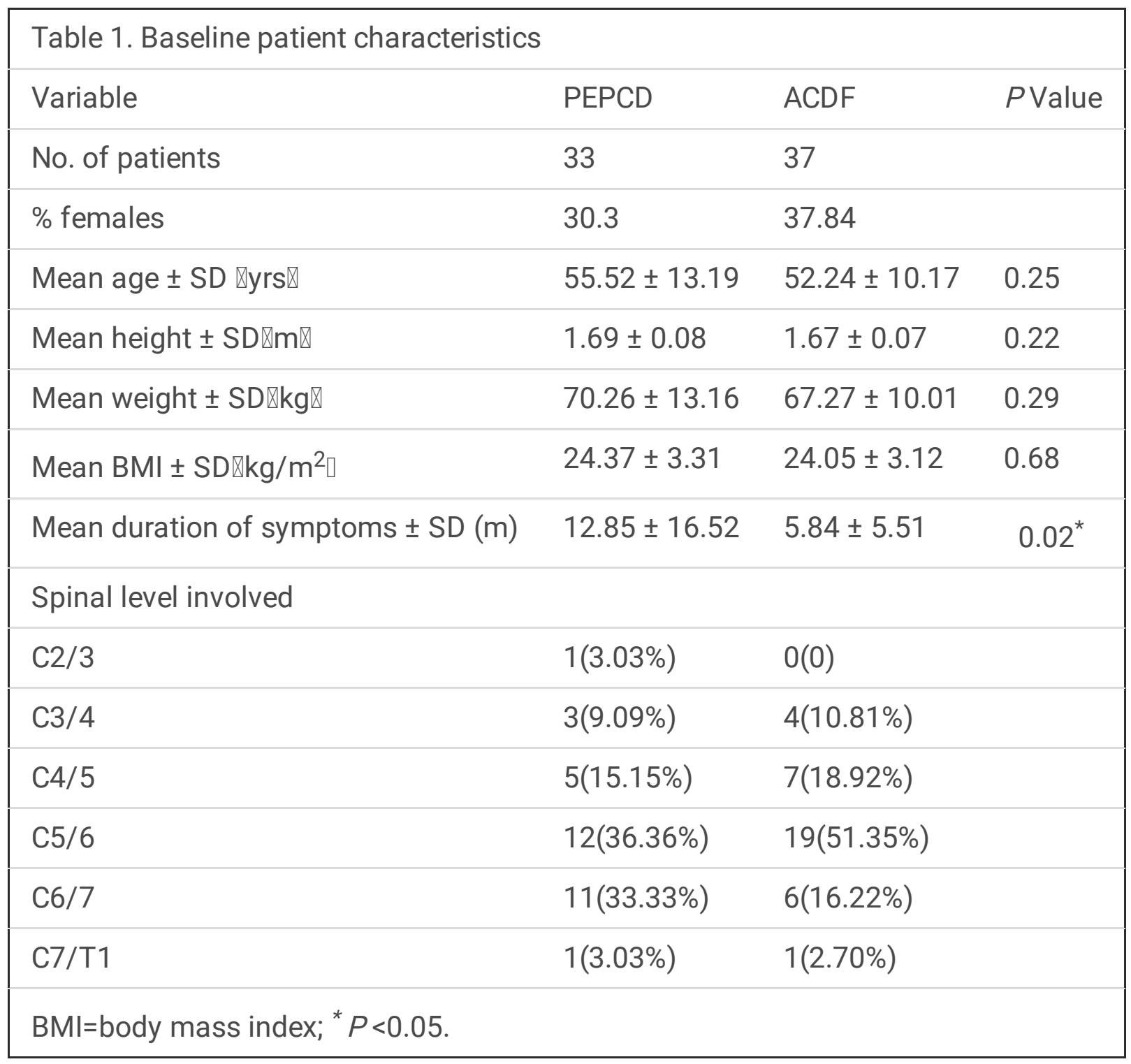

The intra-operative parameters including operative time, intraoperative blood loss, length of hospital stay (LOHS) and surgical costs were compared between two groups (table.2). The mean operative times for PEPCD and ACDF assisted groups were $96.87 \pm 30.70$ and $77.95 \pm 22.91$ min respectively, the mean operative times of ACDF was much shorter than in the PEPCD group at $19 \mathrm{~min}$ ( $P>0.05$ ). Mean blood loss in ACDF (49.19 $\pm 17.70 \mathrm{ml})$ was much higher than in PEPCD group $(28.39 \pm 20.83 \mathrm{ml})$, which was statistically significant $(P<0.001)$. The average LOHS for PEPCD $(2.74 \pm 1.39 \mathrm{~d})$ was significantly shorter compared to ACDF $(4.41 \pm 2.23)(P<0.001)$. The average surgical costs of hospital stay proved to be significantly lower for PEPCD procedures compared to open: 24938.65 and 55654.40 (RMB $¥)(P<0.001)$. The average back to work/ full activity for PEPCD was $2.16 \pm 1.39$ weeks, which was much shorter than that of ACDF $(5.41 \pm 2.90, P<0.05)$. 


\begin{tabular}{|c|c|c|c|}
\hline Outcome Variable & PEPCD & ACDF & $P$ Value \\
\hline Blood Loss (ml) & $28.39 \pm 20.83$ & $49.19 \pm 17.70$ & $<0.001$ \\
\hline Operative Time (min) & $96.87 \pm 30.70$ & $77.95 \pm 22.91$ & 0.005 \\
\hline LOHS (d) & $2.74 \pm 1.39$ & $4.41 \pm 2.23$ & $<0.001$ \\
\hline Surgical costs (RMB $¥)$ & $24938.65 \pm 159.06 .55$ & $55654.40 \pm 9411.00$ & $<0.001$ \\
\hline Back to work/ Full activity (W) & $2.16 \pm 1.39$ & $5.41 \pm 2.90$ & $<0.001$ \\
\hline
\end{tabular}

LOHS: Length of Hospital Stay.

\section{Clinical outcome measures}

The mean follow-up time was 48.5 month ranging from 36 to 66 month. The patient was followed up and recorded by a specific person through outpatient and/or telephone. As showed in table 3, the mean NDI, neck and arm VAS scores were statistically similar at all time periods. From the VAS score, we found that both groups had significant upper limb pain (6.74 \pm 1.88 [PEPCD] vs $6.92 \pm 1.60$ [ACDF]; $P=0.67)$, and most patients had varying degrees of neck pain and discomfort, and the patient's upper limb pain symptoms were significantly heavier than neck pain. The neurological symptoms of neck pain and upper limb pain were significantly relieved in patients at different follow-up time, and there was no significant difference in VAS scores between the two groups at different follow-up times. We can see that both groups of patients had significant cervical dysfunction before surgery, but did not have significant statistical differences; There was no significant difference in NDI between the two groups at different follow-up times ( $P>0.05)$. From the NDI and VAS scores, we learned that ACDF and PEPCD surgery can effectively treat CSR, and $3,6,12,24,36,48,60$ month $^{\square}$ follow-up results were no significant differences. 


\begin{tabular}{|c|c|c|c|}
\hline scale & PEPCD & ACDF & $P$ value \\
\hline \multicolumn{4}{|c|}{ NO. Patients } \\
\hline Preop & 33 & 37 & \\
\hline 3 month & 33 & 37 & \\
\hline 6 month & 33 & 36 & \\
\hline 12 month & 32 & 36 & \\
\hline 24 month & 32 & 34 & \\
\hline 36 month & 30 & 34 & \\
\hline 48 month & 30 & 33 & \\
\hline 60 month & 29 & 31 & \\
\hline \multicolumn{4}{|l|}{ NDI } \\
\hline Preop & $27.26 \pm 9.66$ & $29.13 \pm 9.40$ & 0.42 \\
\hline 3 month & $10.38 \pm 4.80$ & $11.57 \pm 5.47$ & 0.35 \\
\hline 6 month & $9.23 \pm 3.58$ & $10.55 \pm 4.69$ & 0.23 \\
\hline 12 month & $10.86 \pm 4.59$ & $10.17 \pm 6.67$ & 0.39 \\
\hline 24 month & $10.44 \pm 3.68$ & $10.38 \pm 3.98$ & 0.45 \\
\hline 36 month & $9.81 \pm 3.06$ & $10.94 \pm 4.42$ & 0.36 \\
\hline 48 month & $9.94 \pm 2.75$ & $9.38 \pm 5.98$ & 0.40 \\
\hline 60 month & $10.16 \pm 2.82$ & $10.03 \pm 4.71$ & 0.46 \\
\hline \multicolumn{4}{|l|}{ Neck VAS } \\
\hline Preop & $2.06 \pm 1.44$ & $2.92 \pm 1.55$ & $0.02^{*}$ \\
\hline 3 month & $1.71 \pm 1.04$ & $2.00 \pm 1.00$ & 0.27 \\
\hline 6 month & $1.15 \pm 0.92$ & $1.29 \pm 0.87$ & 0.55 \\
\hline 12 month & $1.08 \pm 0.74$ & $1.16 \pm 0.92$ & 0.52 \\
\hline 24 month & $1.23 \pm 0.86$ & $1.19 \pm 0.95$ & 0.49 \\
\hline 36 month & $1.18 \pm 0.82$ & $1.16 \pm 0.88$ & 0.51 \\
\hline 48 month & $1.13 \pm 0.85$ & $1.14 \pm 0.94$ & 0.47 \\
\hline 60 month & $1.09 \pm 1.31$ & $1.17 \pm 1.44$ & 0.35 \\
\hline
\end{tabular}




\begin{tabular}{|llll|}
\hline Arm VAS & & & \\
\hline Preop & $6.74 \pm 1.88$ & $6.92 \pm 1.60$ & 0.67 \\
\hline 3 month & $1.84 \pm 1.32$ & $1.59 \pm 1.21$ & 0.43 \\
\hline 6 month & $1.50 \pm 1.17$ & $1.45 \pm 0.96$ & 0.70 \\
\hline 12 month & $1.50 \pm 1.40$ & $1.61 \pm 1.24$ & 0.41 \\
\hline 24 month & $1.48 \pm 1.23$ & $1.54 \pm 1.58$ & 0.61 \\
\hline 36 month & $1.46 \pm 1.42$ & $1.49 \pm 1.55$ & 0.72 \\
\hline 48 month & $1.49 \pm 1.51$ & $1.45 \pm 1.34$ & 0.77 \\
\hline 60 month & $1.52 \pm 1.38$ & $1.50 \pm 1.36$ & 0.81 \\
\hline
\end{tabular}

${ }^{*} P<0.05$.

There was no serious complication in both groups. Severe complications, including cerebrospinal fluid leakage, paralysis, hoarseness, postoperative bleeding compression, infection and so on. In the ACDF group, there were five patients with temporary swallowing pain and foreign body sensation and the symptoms were relieved within $2 \mathrm{w}$. one patient due to scar body induced neck appearance damage. In the PEPCD group, one patient had excessive bleeding during surgery, resulting in blurred vision, surgical methods were changed to cervical posterior MED. Symptom of another patient was not improved on the second day after surgery, and ACDF was performed on the third day. ACDF surgery confirmed that the target segment protrusion of patients with ossification, and nerve root canal stenosis. The operative failure rate of PEPCD group was $6.06 \%$, which was significantly higher than that of ACDF group. There were no further complications, such as infection, spondylodiscitis or thrombosis.

\section{Radiologic Findings}

In this study, there were no cases of cervical vertebral instability, cervical disc herniation, kyphosis or lordosis after operation in both group. The results of cervical curvature showed that the preoperative $\mathrm{C} 2-7$ lordosis of the ACDF and PEPCD group was $9.99 \pm 3.66$ and $10.91 \pm 5.68$ respectively. At the end of the follow-up, the lateral radiographs of the cervical spine showed that the $\mathrm{C} 2-7$ lordosis of the two groups were significantly increased (ACDF $18.56 \pm 5.28 \triangle$ PEPCD $13.89 \pm 3.35$ ), and the ACDF group was significantly higher than that of PEPCD $(P<0.05)$. At the last follow-up, MRI found that there were no significant changes in the adjacent intervertebral discs in the two groups. MRI showed that the intervertebral disc degeneration grade of PEPCD group was significantly increased from $3.84 \pm 1.24$ before surgery to $4.39 \pm 1.08(P<0.05)$ at the last follow-up. The results showed that PEPCD could significantly increase the degeneration of intervertebral disc. In the PEPCD group, there was no significant decrease in the intervertebral height index (22.50 \pm 1.39 VS $22.39 \pm 1.32 P=0.071)$ at the last follow-up (figure. 3). In the ACDF group, no significant surgical segmental vertebral height loss, prosthetic sedimentation or pseudoarthrosis was observed during follow-up. In the PEPCD group, with the extension 
of time, CT three-dimensional reconstruction found that the removal of the cervical lamina area gradually reduced $₫$ figure. 4 \.

Figure.3 The changes of C2-7 lordosis in patients with ACDF and PEPCD before and the last follow-up. A, B: cervical lateral radiographs of PEPCD at the time of preoperative and final follow-up, respectively. C, D: cervical lateral radiographs of patients with ACDF before and at the last follow-up, respectively. E: C2-7 lordosis data for two groups of patients before and at the last follow-up. Data was mean $\pm S D, * P<0.05$.

Figure.4 48 years old male patient presented with a three dimensional CT after surgery. A: the arrow refers to the range of three-dimensional CT decompression on the 1 day after surgery; $\mathrm{B}$ : the arrow refers to the range of three-dimensional CT decompression at the end of the 2 year after surgery.

\section{Discussion}

In this study, we retrospectively analyzed the clinical data and surgical results of ACDF and PEPCD in the treatment of single-segment CSR. Our study found that PEPCD treatment of single-segment CSR was similar to ACDF in terms of early and mid-term effects. Both of which can effectively remove nerve root compression to relieve symptoms, which is similar to previous findings [21, 23, 26, 27]. Compared with ACDF, PEPCD can significantly reduce the surgical trauma (reduced blood loss, shortened hospital stay), to promote postoperative rehabilitation (Back to work / Full activity), reduce economic and social burden (lower hospitalization costs) [20,31]. We found that the ACDF and PEPCD can significant improve C2-7 lordosis, and the $\mathrm{C} 2-7$ lordosis improved more in the ACDF group when compared with that of PEPCD. In the PEPCD group, 2 patients due to intraoperative or postoperative symptoms did not significantly alleviate, thus changing the surgical procedure. There were no cases of revision surgery due to recurrence of symptoms. The failure rate PEPCD were significantly higher than those of ACDF group.

With the changes in modern life and working style, the incidence of neck and shoulder pain and other diseases caused by degenerative intervertebral discs is increasing [32]. CSR is a common cause of neck pain and upper limb pain [33]. Through the control of neck activities, physical therapy, analgesic, dehydration, neurotrophic drug therapy, symptoms can be alleviated [3, 34]. For long-term, severe CSR patients, surgical treatment is required. With the development of minimally invasive endoscopic surgery in recent years, more and more people have reported the application of PEPCD in the treatment of cervical spondylosis $[21,26,27,35,36]$. PEPCD surgery not only have advantages of cervical posterior keyhole surgery and MED surgery, but also has a smaller trauma, better visual field, more accurate decompression positioning, surgical operation more accurate and so on. With the further optimization of endoscopic devices, surgical operation is more simple. The cervical lamina is relatively flat and there is a natural lamina intervertebral space, which helps to locate and place the endoscopic channel during operation. It is very practical.

In this study, patients with PEPCD were treated with a customized plaster bed based on the size of the patient. On one hand, the plaster bed was convenient for intraoperative X-ray fluoroscopy. On the other hand, the plaster bed, which was customized according to the patient's body, was convenient for 
regulating the position of the patient and preventing intraoperative pressure. In the course of surgery, the patient's position is the head side raised $20-30^{\circ}$ prone position. The aim is to reduce the pressure in the spinal canal venous plexus, thereby reducing intraoperative bleeding [37]. The patient's cervical spine is in a slightly flexed position, widening the gap between the vertebrae and enlarging the operating space. Disc herniation, especially the prominent below the nerve root, will increase the nerve root tension. When the patient in general anesthesia, the neck muscles will be in a relaxed state. If the cervical spine in the excessive flexion, nerve root will be excessive traction, which may increase the rate of iatrogenic injury. The double needle technique and the "K" point are used to determine the position of the target segment and the working channel. During the operation, according to the position of the double needle and the $\mathrm{K}$ point in the X-ray anteroposterior radiograph, the position of the endoscope working channel of the $\mathrm{K}$ point can be accurately positioned by adjusting the needle 1-2 times. The lamina gap is located by clearing the soft tissue around the $\mathrm{K}$ point.

Hemorrhage during the PEPCD is an important factor affecting the success of surgery. There are 3 types of bleeding in chief, one is the soft tissue around the vertebral column, one is the spinal cord venous plexus bleeding, the other is the upper and lower vertebral lamina of cancellous bone. Radiofrequency electrocoagulation can effectively stop the bleeding of soft tissue around the lamina. The vertebral vein venous hemorrhage can be decreased through the position adjustment to reduce venous plexus pressure. In our clinical practice, we found that increased saline pressure can reduce the intraoperative spinal canal venous plexus bleeding. Bleeding from the upper and lower vertebral cancellous bone is difficult to deal with. In this study, there was one case of intraoperative vertebral hemorrhage, which seriously affected the surgical field of vision, and we had to change the operation plan finally. There are some ways to decrease bleeding in the literature. Using controlled hypotension [38, 39], local vasoconstrictor [40] and new hemostatic biological materials [41] can reduce bleeding. It had been reported that the use of hot saline irrigation can effectively reduce the bleeding of functional endoscopic sinus surgery (FESS) [42]. Whether thermal saline can reduce the bleeding in PEPCD surgery, and thermal saline effect on spinal cord need further study.

For the upper and lower lamina decompression range, we believed that to minimize the destruction of the articular process while ensuring adequate decompression of the nerve root. In open surgery, biomechanical studies had shown that removal of more than $50 \%$ of articular processes can cause cervical instability [43]. PEPCD surgery reduced the stripping of ligaments and muscles around the spine, so the probability of cervical instability was reduced. In this study, three-dimensional reconstruction of CT showed that with the prolongation of time, the area of the cervical vertebral plate was gradually decreased. The results showed that the bited lamina had the trend of fracture healing under the influence of biomechanics and internal microenvironment. This healing can further enhance the stability of the vertebral body and prevent the occurrence of postoperative vertebral instability. Therefore, we believe that the first element in the PEPCD procedure is sufficient laminectomy to achieve adequate decompression. Facet joint resection should be controlled within $50 \%$, in the course of surgery it may be appropriate to enlarge the standard according to decompression. 
The essence of PEPCD operation is the further optimization and extension of keyhole and MED. The technique of endoscopic technique is used to remove the small joints and the prominent nucleus pulposus through a more minimally invasive and more accurate technique, so as to achieve the purpose of nerve root canal enlargement and nerve root decompression. In this study, we confirmed that the clinical effect of PEPCD in the treatment of CSR is equivalent to that of ACDF, and the surgical trauma is smaller and the postoperative recovery is faster. PEPCD surgery is limited by its own technical characteristics, adapted to cervical disc herniation and small joint hyperplasia induced intervertebral foramen stenosis; contraindications include central cervical disc herniation, cervical spondylotic myelopathy, posterior longitudinal ligament ossification or cervical unstable and so on [20,44]. However, with the development of endoscopic techniques, PEPCD has also been applied to multi-segment cervical spondylosis [27], cervical spondylotic myelopathy, and achieved good early postoperative effect. In this study, the number of samples and the follow-up time were limited, and no re-protrusion was observed. However, there was reports that the re-protrusion of PEPCD was $3.4 \%$ for 2 years fellow-up [21]. Reherniation after minimally invasive surgery has been a problem for spine surgeons. As surgery only removed the prominent nucleus pulposus, intervertebral disc rupture still exists, so the residual nucleus pulposus can still re-herniation through intervertebral disc rupture. It had been reported that the use of polymethyl methacrylate (PMMA) closure in the surgery can significantly reduce the probability of postoperative re-herniation [45]. Due to the limitations of material technology and lack of long-term follow-up, clinical application is not extensive. Due to the steep learning curve of PEPCD surgery, and the requirement of the ability of understanding the three-dimensional anatomical structure during PEPCD, the development of the operation is limited.

\section{Conclusion}

For patients with CSR, PEPCD had similar clinical early and intermediate outcomes when compared with ACDF, with less trauma and faster recovery. PEPCD can be used as an effective treatment for CSR ladder therapy, which is between conservative treatment and interbody fusion. Due to the limited number of cases, short follow-up time, long term clinical efficacy and recurrence need further study.

\section{Abbreviations}

CSR: cervical spondylotic radiculopathy;

PEPCD: percutaneous endoscopic posterior cervical discectomy;

ACDF: anterior cervical decompression and fusion;

DHI: disc height index;

NDI: neck disability index;

VAS: visual analog scale; 
MED: micro Endoscopic Discectomy;

BMI: body mass index;

LOHS: length of Hospital Stay;

\section{Declarations}

\section{Ethics approval and consent to participate:}

This study was approved by the Ethics Committee of the Second Military Medical University. All patients also agreed to participate in the study.

Consent for publication:

All authors reviewed and approved the manuscript for publication.

\section{Availability of data and materials:}

Available.

\section{Competing interests:}

The authors declare no competing financial interests.

\section{Funding:}

This work supported by National Natural Science Foundation of China (Grant no. 81472071 and Grant no.81301537).

\section{Authors' contributions:}

Xiaodong Huang and Weiheng Wang are responsible for the design and implementation of the experiment; Qingxi Meng MD and Jiangming Yu MD are responsible for the measurement and analysis of the results; Xiaojian Ye is responsible for the overall planning of the experiment.

\section{Acknowledgements:}

We thank Xiangqun Yang MD, PhD (Institute of Biomedical Engineering, Second Military Medical University), Guoying Deng MD (Department of Orthopaedic Surgery, Shanghai No.1 People's Hospital) for their help to sort data.

\section{References}


1. Nikolaidis I, Fouyas IP, Sandercock PA, Statham PF (2010) Surgery for cervical radiculopathy or myelopathy. The Cochrane database of systematic reviews:Cd001466. doi:

10.1002/14651858.CD001466.pub3

2. Terai H, Suzuki A, Toyoda H, Yasuda H, Kaneda K, Katsutani H, Nakamura H (2014) Tandem keyhole foraminotomy in the treatment of cervical radiculopathy: retrospective review of 35 cases. Journal of orthopaedic surgery and research 9:38. doi: 10.1186/1749-799x-9-38

3. Matz PG, Anderson PA, Holly LT, Groff MW, Heary RF, Kaiser MG, Mummaneni PV, Ryken TC, Choudhri TF, Vresilovic EJ, Resnick DK (2009) The natural history of cervical spondylotic myelopathy. Journal of neurosurgery Spine 11:104-111. doi: 10.3171/2009.1.spine08716

4. Thoomes EJ (2016) Effectiveness of manual therapy for cervical radiculopathy, a review. Chiropractic \& manual therapies 24:45. doi: 10.1186/s12998-016-0126-7

5. Hult L (1951) Retroperitoneal disc fenestration in low-back pain and sciatica; a preliminary report. Acta orthopaedica Scandinavica 20:342-348

6. Liu WJ, Hu L, Chou PH, Wang JW, Kan WS (2016) Comparison of Anterior Cervical Discectomy and Fusion versus Posterior Cervical Foraminotomy in the Treatment of Cervical Radiculopathy: A Systematic Review. Orthopaedic surgery 8:425-431. doi: 10.1111/os.12285

7. Shao MM, Chen CH, Lin ZK, Wang XY, Huang QS, Chi YL, Wu AM (2016) Comparison of the more than 5-year clinical outcomes of cervical disc arthroplasty versus anterior cervical discectomy and fusion: A protocol for a systematic review and meta-analysis of prospective randomized controlled trials. Medicine 95:e5733. doi: 10.1097/md.0000000000005733

8. Takayasu M (2009) [Less invasive surgery for cervical spine]. Brain and nerve = Shinkei kenkyu no shinpo 61:637-644

9. Takeuchi M, Takayasu M, Yasuda M, Kamiya M, Inukai T, Matsuo N, Osuka K (2012) Transvertebral anterior key hole foraminotomy without fusion for the cervicothoracic junction. Acta neurochirurgica 154:1797-1802. doi: 10.1007/s00701-012-1484-0

10. Xiao S, Liang Z, Wei W, Ning J (2017) Zero-profile anchored cage reduces risk of postoperative dysphagia compared with cage with plate fixation after anterior cervical discectomy and fusion. European spine journal : official publication of the European Spine Society, the European Spinal Deformity Society, and the European Section of the Cervical Spine Research Society 26:975-984. doi: 10.1007/s00586-016-4914-5

11. Veeravagu A, Cole T, Jiang B, Ratliff JK (2014) Revision rates and complication incidence in singleand multilevel anterior cervical discectomy and fusion procedures: an administrative database study. The spine journal : official journal of the North American Spine Society 14:1125-1131. doi: 10.1016/j.spinee.2013.07.474

12. Ma Z, Ma X, Yang H, Guan X, Li X (2017) Anterior cervical discectomy and fusion versus cervical arthroplasty for the management of cervical spondylosis: a meta-analysis. European spine journal : official publication of the European Spine Society, the European Spinal Deformity Society, and the 
European Section of the Cervical Spine Research Society 26:998-1008. doi: 10.1007/s00586-0164779-7

13. Seo M, Choi D (2008) Adjacent segment disease after fusion for cervical spondylosis; myth or reality? British journal of neurosurgery 22:195-199. doi: 10.1080/02688690701790605

14. Lidar Z, Salame K (2011) Minimally invasive posterior cervical discectomy for cervical radiculopathy: technique and clinical results. Journal of spinal disorders \& techniques 24:521-524. doi:

10.1097/BSD.0b013e31820679e3

15. Heary RF, Ryken TC, Matz PG, Anderson PA, Groff MW, Holly LT, Kaiser MG, Mummaneni PV, Choudhri TF, Vresilovic EJ, Resnick DK (2009) Cervical laminoforaminotomy for the treatment of cervical degenerative radiculopathy. Journal of neurosurgery Spine 11:198-202. doi:

10.3171/2009.2.spine08722

16. Hosono N, Yonenobu K, Ono K (1996) Neck and shoulder pain after laminoplasty. A noticeable complication. Spine 21:1969-1973

17. Kaptain GJ, Simmons NE, Replogle RE, Pobereskin L (2000) Incidence and outcome of kyphotic deformity following laminectomy for cervical spondylotic myelopathy. Journal of neurosurgery 93:199-204

18. Siebert WE, Berendsen BT, Tollgaard J (1996) [Percutaneous laser disk decompression. Experience since 1989]. Der Orthopade 25:42-48

19. Ahn Y, Lee SH, Shin SW (2005) Percutaneous endoscopic cervical discectomy: clinical outcome and radiographic changes. Photomedicine and laser surgery 23:362-368. doi: 10.1089/pho.2005.23.362

20. Abbas SF, Spurgas MP, Szewczyk BS, Yim B, Ata A, German JW (2016) A comparison of minimally invasive posterior cervical decompression and open anterior cervical decompression and instrumented fusion in the surgical management of degenerative cervical myelopathy. Neurosurgical focus 40:E7. doi: 10.3171/2016.3.focus1650

21. Ruetten S, Komp M, Merk H, Godolias G (2008) Full-endoscopic cervical posterior foraminotomy for the operation of lateral disc herniations using 5.9-mm endoscopes: a prospective, randomized, controlled study. Spine 33:940-948. doi: 10.1097/BRS.0b013e31816c8b67

22. Adamson TE (2001) Microendoscopic posterior cervical laminoforaminotomy for unilateral radiculopathy: results of a new technique in 100 cases. Journal of neurosurgery 95:51-57

23. Ruetten S, Komp M, Merk H, Godolias G (2007) A new full-endoscopic technique for cervical posterior foraminotomy in the treatment of lateral disc herniations using 6.9-mm endoscopes: prospective 2year results of 87 patients. Minimally invasive neurosurgery : MIN 50:219-226. doi: 10.1055/s-2007985860

24. Mu X, Wei J, Li P (2015) What were the advantages of microendoscopic discectomy for lumbar disc herniation comparing with open discectomy: a meta-analysis? International journal of clinical and experimental medicine 8:17498-17506

25. Zhou Y, Wang M, Wang J, Chu TW, Zhang ZF, Li CQ (2009) Clinical experience and results of lumbar microendoscopic discectomy: a study with a five-year follow-up. Orthopaedic surgery 1:171-175. doi: 
10.1111/j.1757-7861.2009.00039.x

26. Gibson JN, Subramanian AS, Scott CE (2017) A randomised controlled trial of transforaminal endoscopic discectomy vs microdiscectomy. European spine journal : official publication of the European Spine Society, the European Spinal Deformity Society, and the European Section of the Cervical Spine Research Society 26:847-856. doi: 10.1007/s00586-016-4885-6

27. Youn MS, Shon MH, Seong YJ, Shin JK, Goh TS, Lee JS (2017) Clinical and radiological outcomes of two-level endoscopic posterior cervical foraminotomy. European spine journal : official publication of the European Spine Society, the European Spinal Deformity Society, and the European Section of the Cervical Spine Research Society. doi: 10.1007/s00586-017-5017-7

28. Toksoy A, Bektas F, Eken C, Ceken K, Cete Y (2010) Value of the swimming position and arm traction in visualizing the cervicothoracic junction over the standard lateral cervical X-ray. International journal of emergency medicine 3:85-90. doi: 10.1007/s12245-010-0159-y

29. Emery SE, Bolesta MJ, Banks MA, Jones PK (1994) Robinson anterior cervical fusion comparison of the standard and modified techniques. Spine 19:660-663

30. Pfirrmann CW, Metzdorf A, Zanetti M, Hodler J, Boos N (2001) Magnetic resonance classification of lumbar intervertebral disc degeneration. Spine 26:1873-1878

31. Winder MJ, Thomas KC (2011) Minimally invasive versus open approach for cervical laminoforaminotomy. The Canadian journal of neurological sciences Le journal canadien des sciences neurologiques 38:262-267

32. Raj PP (2008) Intervertebral disc: anatomy-physiology-pathophysiology-treatment. Pain practice : the official journal of World Institute of Pain 8:18-44. doi: 10.1111/j.1533-2500.2007.00171.x

33. Al Barbarawi MM, Allouh MZ (2015) Cervical lateral mass screw-rod fixation: Surgical experience with 2500 consecutive screws, an analytical review, and long-term outcomes. British journal of neurosurgery 29:699-704. doi: 10.3109/02688697.2015.1026798

34. Tracy JA, Bartleson JD (2010) Cervical spondylotic myelopathy. The neurologist 16:176-187. doi: 10.1097/NRL.0b013e3181da3a29

35. Lee JH, Lee SH (2014) Clinical and radiographic changes after percutaneous endoscopic cervical discectomy: a long-term follow-up. Photomedicine and laser surgery 32:663-668. doi: 10.1089/pho.2014.3806

36. Ahn Y, Lee SH, Chung SE, Park HS, Shin SW (2005) Percutaneous endoscopic cervical discectomy for discogenic cervical headache due to soft disc herniation. Neuroradiology 47:924-930. doi: 10.1007/s00234-005-1436-y

37. Coric $D$, Adamson $T$ (2008) Minimally invasive cervical microendoscopic laminoforaminotomy. Neurosurgical focus 25:E2. doi: 10.3171/foc/2008/25/8/e2

38. Boezaart AP, van der Merwe J, Coetzee A (1995) Comparison of sodium nitroprusside- and esmololinduced controlled hypotension for functional endoscopic sinus surgery. Canadian journal of anaesthesia $=$ Journal canadien d'anesthesie 42:373-376. doi: 10.1007/bf03015479 
39. Cardesin A, Pontes C, Rosell R, Escamilla Y, Marco J, Escobar MJ, Bernal-Sprekelsen M (2014) Hypotensive anaesthesia and bleeding during endoscopic sinus surgery: an observational study. European archives of oto-rhino-laryngology : official journal of the European Federation of Oto-RhinoLaryngological Societies (EUFOS) : affiliated with the German Society for Oto-Rhino-Laryngology Head and Neck Surgery 271:1505-1511. doi: 10.1007/s00405-013-2700-0

40. Higgins TS, Hwang PH, Kingdom TT, Orlandi RR, Stammberger H, Han JK (2011) Systematic review of topical vasoconstrictors in endoscopic sinus surgery. The Laryngoscope 121:422-432. doi: 10.1002/lary. 21286

41. Thongrong C, Kasemsiri P, Carrau RL, Bergese SD (2013) Control of bleeding in endoscopic skull base surgery: current concepts to improve hemostasis. ISRN surgery 2013:191543. doi: $10.1155 / 2013 / 191543$

42. Gan EC, Alsaleh S, Manji J, Habib AR, Amanian A, Javer AR (2014) Hemostatic effect of hot saline irrigation during functional endoscopic sinus surgery: a randomized controlled trial. International forum of allergy \& rhinology 4:877-884. doi: 10.1002/alr.21376

43. Zdeblick TA, Abitbol JJ, Kunz DN, McCabe RP, Garfin S (1993) Cervical stability after sequential capsule resection. Spine 18:2005-2008

44. Shin DA, Kim KN, Shin HC, Yoon DH (2008) The efficacy of microendoscopic discectomy in reducing iatrogenic muscle injury. Journal of neurosurgery Spine 8:39-43. doi: 10.3171/spi-08/01/039

45. Korinth MC, Kruger A, Oertel MF, Gilsbach JM (2006) Posterior foraminotomy or anterior discectomy with polymethyl methacrylate interbody stabilization for cervical soft disc disease: results in 292 patients with monoradiculopathy. Spine 31:1207-1214; discussion 1215-1206. doi:

10.1097/01.brs.0000217604.02663.59

\section{Figures}



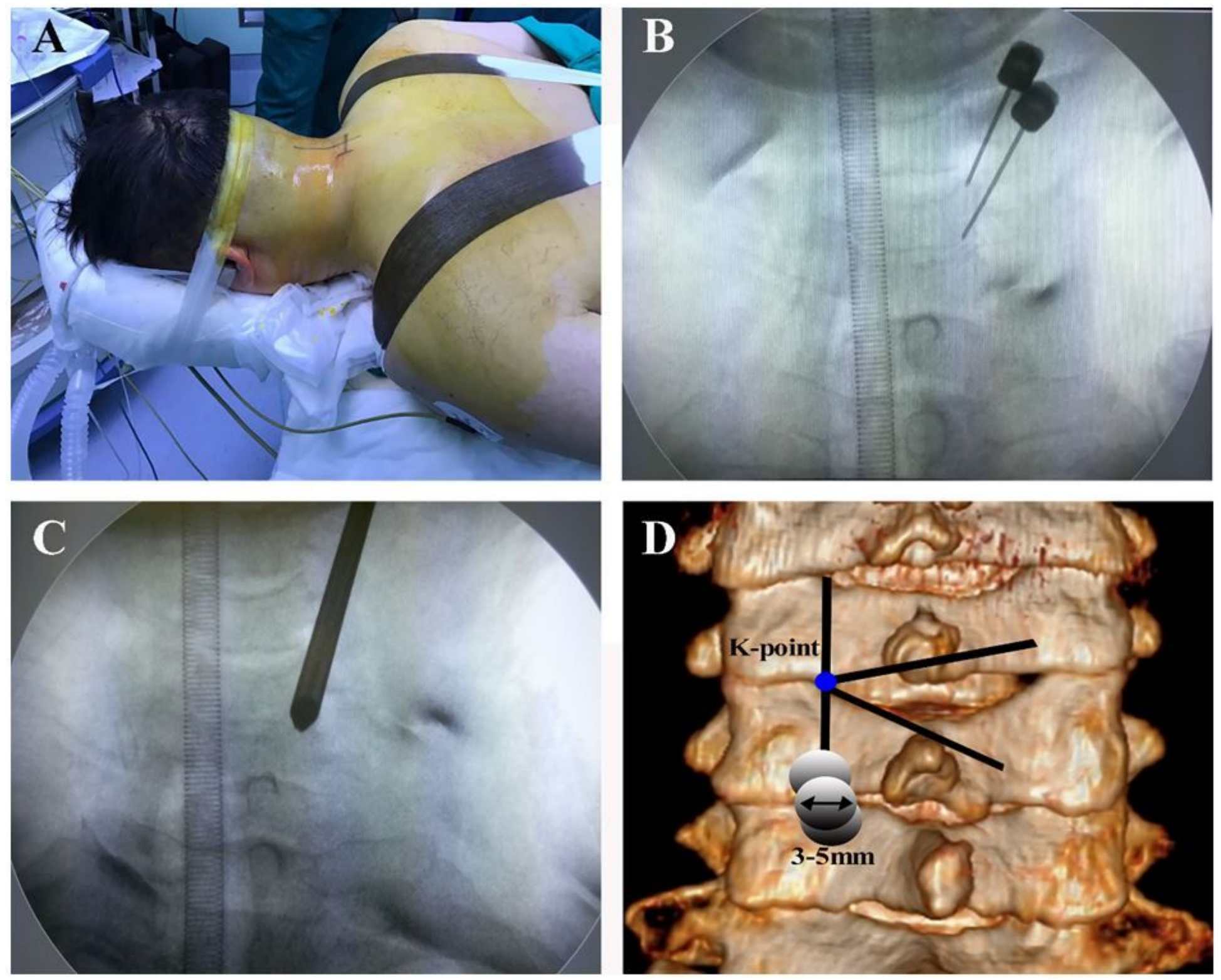

Figure 1

Position and orientation during operation. A: the patient in the prone position on a customized plaster bed; $\mathrm{B}$ : Two positioning pins used to determine the target gap and $\mathrm{K}$ point; $\mathrm{C}$ : The cervical spine radiograph shows that the expansion sleeve is located near the $\mathrm{K}$ point of the gap; $\mathrm{D}$ : Three dimensional $\mathrm{CT}$ display of $\mathrm{K}$ point and the range of intraoperative laminectomy. 

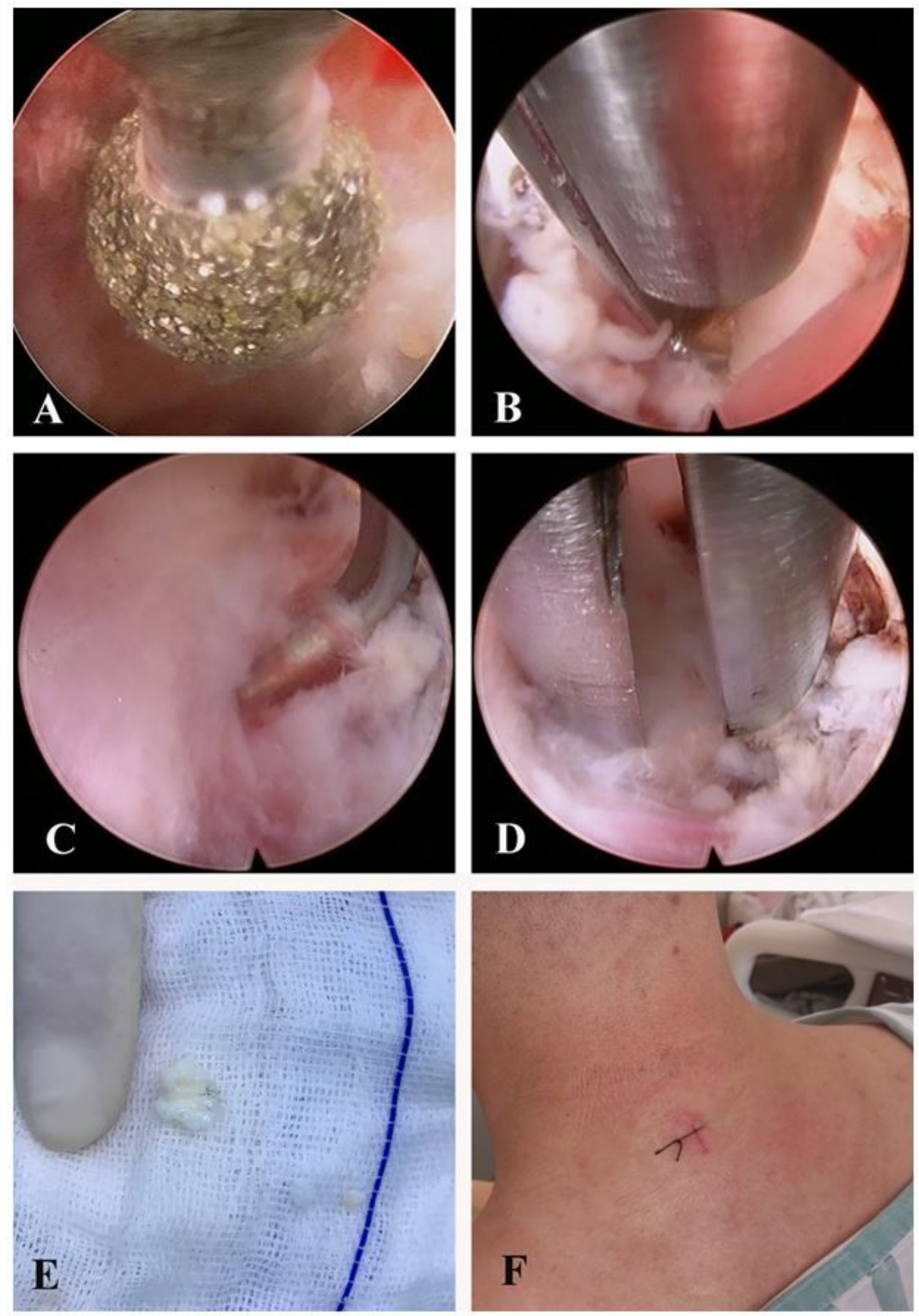

\section{Figure 2}

Intraoperative visual field and postoperative incision. A: Dynamic grinding system for removal of lamina; $B$ : Vertebral lamina and ligament were removed by the biting forceps; C: Nerve root probe to detect nerve root canal and nerve root; D囚Removal of herniated intervertebral disc tissue; $\mathrm{E}$ : The prominent nucleus pulposus was removed during operation; F: Postoperative incision. 

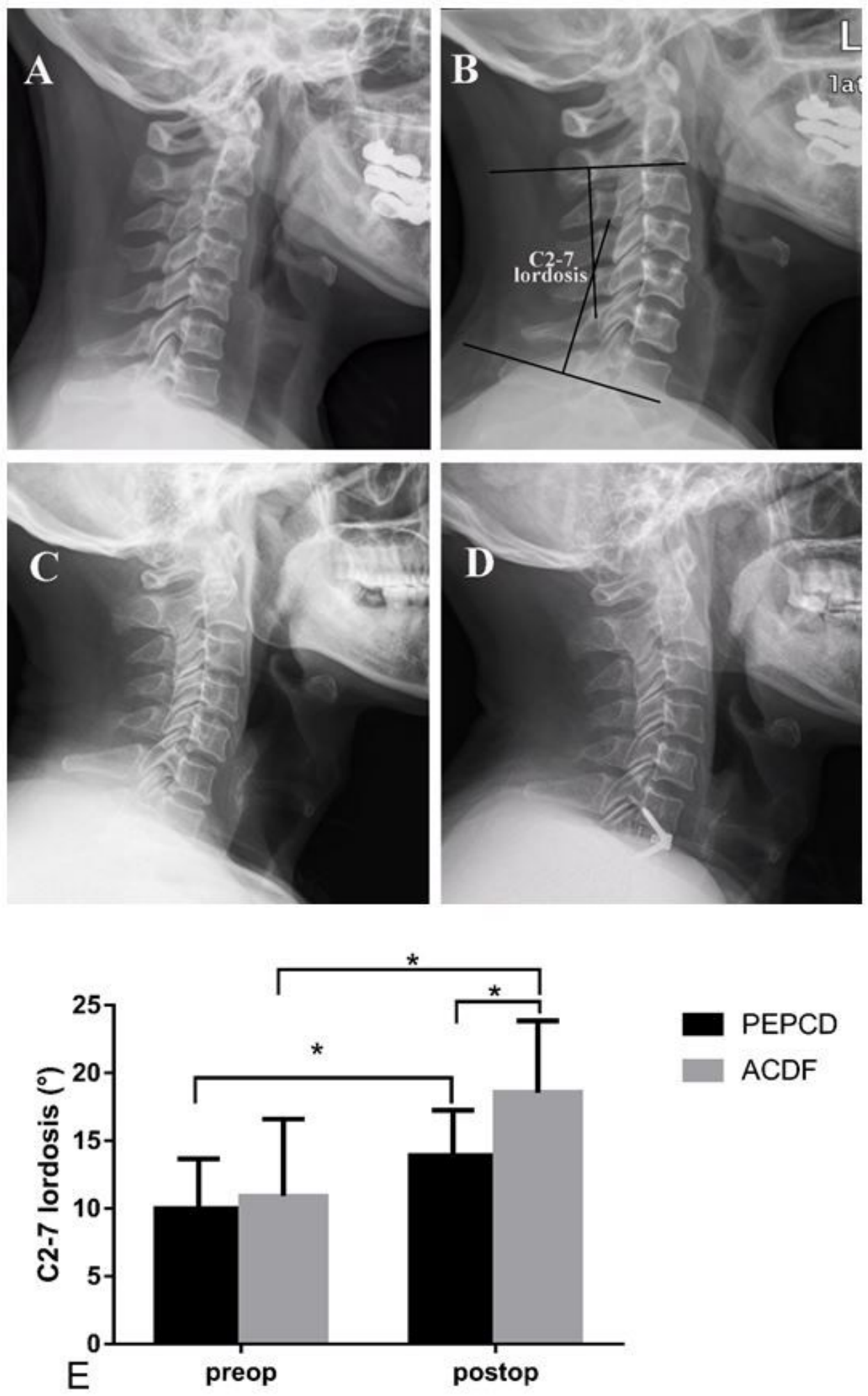

Figure 3

The changes of C2-7 lordosis in patients with ACDF and PEPCD before and at the last follow-up. A, B: cervical lateral radiographs of PEPCD at the time of preoperative and final follow-up, respectively. C, D: cervical lateral radiographs of patients with ACDF before and at the last follow-up, respectively. E: C2-7 lordosis data for two groups of patients before and at the last follow-up. Data was mean $\pm S D, * P<0.05$. 

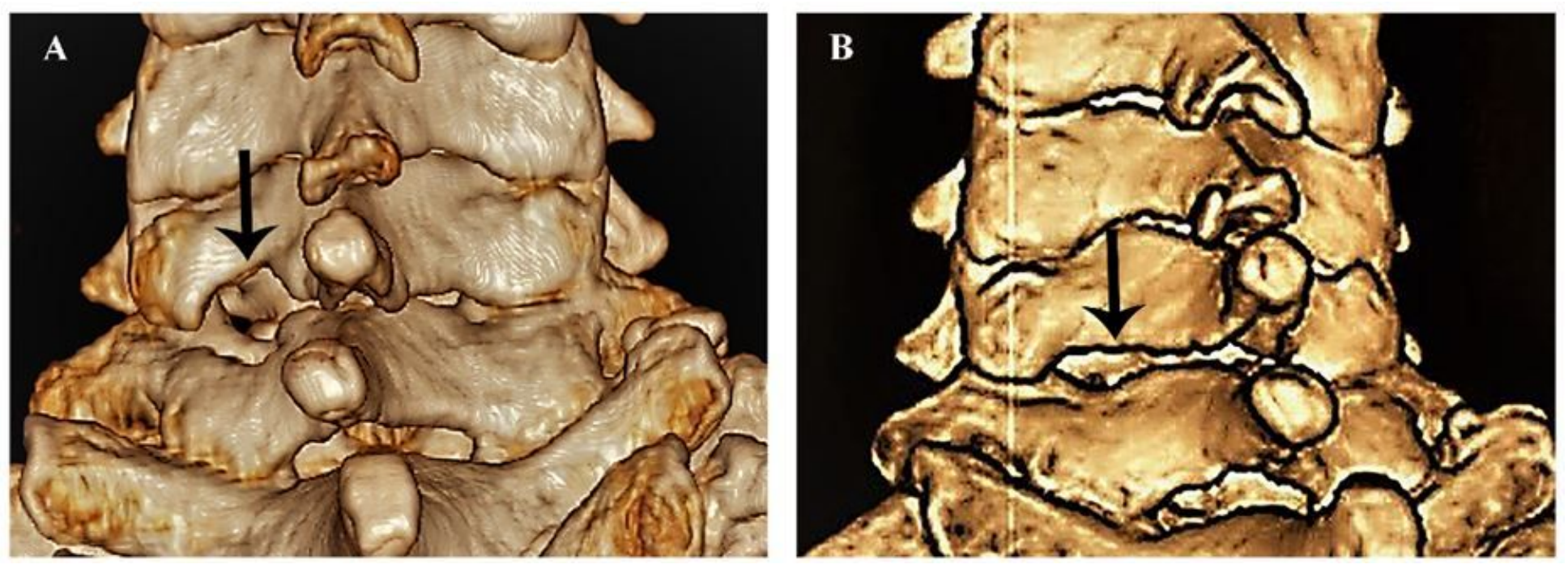

Figure 4

48 years old male patient presented with a three dimensional CT after surgery. A: the arrow refers to the range of three-dimensional CT decompression on the 1 day after surgery; $B$ : the arrow refers to the range of three-dimensional CT decompression at the end of the 2 year after surgery.

\section{Supplementary Files}

This is a list of supplementary files associated with this preprint. Click to download.

- ConflictofInterest.docx 